\title{
Bir üniversite hastanesi personelinin Brusella hakkındaki bilgi, tutum ve davranışlarının değerlendirilmesi
}

\author{
Evaluation of information, attitudes and behaviors of a university hospital staff about \\ Brucella
}

\author{
Mert Özen, Atakan Yılmaz, Reşad Beyoğlu, Murat Seyit, Alten Oskay
}

Gönderilme tarihi:08.06.2020

Kabul tarihi:17.06.2020

\section{Özet}

Amaç: Pamukkale Üniversitesi (PAÜ) Hastanesinde çalışan sağlık profesyonelleri dışındaki personelin sosyodemografik özelliklerinin tanımlanması, Bruselloz ve Brusellozdan korunma hakkındaki bilgilerinin değerlendirilmesi, Brusella enfeksiyonuna yol açabilecek bazı riskli uygulamalarla olan ilişkilerinin belirlenmesi amaçlanmıştır.

Gereç ve yöntem: Araştırmadaki veriler 25 soruluk anket formu ile, yüz yüze görüşme tekniği kullanılarak toplanmıştır. Anketler, PAÜ Hastanesinde uygulanmıştır.

Bulgular: Bruselloz ülkemizde sık görülen bir hastalıktır. Çalışmamıza katılan kişiler farklı yaş gruplarında ve hastanede çalışmasına rağmen Brusellozun sadece hayvanlarla temas sonucu bulaşabildiği $(\% 4,65)(\% 0,58$ $\% 8,72$ ) oranında bilinmiştir. Yaş ve eğitim seviyesi artıkça Brusella hakkındaki bilgi, tutum ve davranışların çoğu zaman olumsuz yönde etkilendiği görülmüştür.

Sonuç: Bruselloz hakkında hastane çalışanları dahil bilgilendirilmeli, hastalığın hayvanlar ve/veya çıkartılarıyla temas sonucu bulaşabileceği riski konusundaki bilinç artırılmalıdır.

Anahtar kelimeler: Brusella, bruselloz, zoonoz hastalıklar.

Özen M, Yılmaz A, Beyoğlu R, Seyit M, Oskay A. Bir üniversite hastanesi personelinin Brusella hakkındaki bilgi, tutum ve davranışlarının değerlendirilmesi. Pam Tıp Derg 2020;13:621-627.

\begin{abstract}
Purpose: The aim of this study is to define the sociodemographic characteristics of the staff other than health professionals working at Pamukkale University (PAU) Hospital, to evaluate their knowledge about Brucellosis and protection of people at risk against it, as well as their relationship with some risky practices that may cause Brucella infection.

Materials and methods: The data of the research were collected using a questionnaire comprising of 25 questions, using face-to-face interview technique. The questionnaires were applied at PAU Hospital.

Results: Brucellosis is a common disease in our country. Although the participants in our study were of different age groups and worked at the hospital environment, only (4.65\%) $(0.58 \%-8.72 \%)$ of them knew that Brucellosis can be transmitted by contact with animals. Increasing age and education level negatively affected the information, attitudes and behaviors about Brucella.

Conclusion: Hospital staff should be informed about Brucellosis, including awareness of the risk that the disease may be transmitted by contact with animals and / or their products or waste.
\end{abstract}

Key words: Brucella, brucellosis, zoonosis diseases.

Ozen M, Yilmaz A, Beyoglu R, Seyit M, Oskay A. Evaluation of information, attitudes and behaviors of a university hospital staff about Brucella. Pam Med J 2020;13:621-627.

Mert Özen, Dr. Öğr. Üye. Pamukkale Üniversitesi, Tıp Fakültesi, Acil Tıp AD, Denizli, Türkiye, e-posta: ozenmert@yahoo.com (orcid.org/0000-0001-6653-3756) (Sorumlu Yazar)

Atakan Yılmaz, Dr. Öğr. Üye. Pamukkale Üniversitesi, Tıp Fakültesi, Acil Tıp AD, Denizli, Türkiye, e-posta: dr_atakanyilmaz@ yahoo.com (orcid.org/0000-0002-9773-5681)

Reşad Beyoğlu, Arş. Gör. Dr. Pamukkale Üniversitesi, Tıp Fakültesi, Acil Tıp AD, Denizli, Türkiye, e-posta: resadbeyoglu@ gmail.com (orcid.org/0000-0001-7321-5131)

Murat Seyit, Dr. Öğr. Üye. Pamukkale Üniversitesi, Tıp Fakültesi, Acil Tıp AD, Denizli, Türkiye, e-posta: muratseyit@yahoo. com (orcid.org/0000-0002-8324-9471)

Alten Oskay, Dr. Öğr. Üye. Pamukkale Üniversitesi, Tıp Fakültesi, Acil Tıp AD, Denizli, Türkiye, e-posta: oskayten@gmail.com (orcid.org/0000-0003-4373-6280) 


\section{Giriş}

Brusella küçük $\quad(0,5-0,7 \times 0,6-1,5 \mu m)$, hareketsiz, kapsulsüz, zorunlu aerob, oksidaz ve üreaz pozitif, kokobasil şeklinde gram negatif bakteridir [1]. Bruselloz ise insanlarda ve hayvanlarda, Brusellanın bazı türleri tarafından oluşturulan zoonotik bir hastalıktır. Yavru atma hastalığı, Mal Hastalığı, Peynir Hastalığı, Malta Humması olarak da bilinmektedir. Ülkemizde ve gelişmekte olan ülkelerde yaygın görülmekle birlikte morbiditesi yüksek, mortalitesi ise düşüktür [1, 2].

Bruselloz enfekte hayvanlar aracılığı ile süt ve süt ürünleri, etleri ve vücut sıvılarından insanlara bulaştığı için halk sağlığı açısından da ayrı bir öneme sahiptir. Bulaş yolları arasında bütünlüğü bozulmuş derinin enfekte hayvan sekresyonları ile direkt teması, enfekte aerosollerin inhale edilmesi, süt ürünlerinin pastörize edilmeden tüketilmesi en bilinenleri olup, hastalıktan şüphelenildiğinde bu yönde sorgulama yapılmalıdır. En sık bulaş çiğ süt ve süt ürünleri (krema, peynir, vs.) aracılığıyla olmaktadır [1, 2, 3]. Hastalığın endemik görüldüğü ülkelerde temel bulaşma yolları pastörize edilmemiş süt ve süt ürünlerinin tüketimi iken, gelişmiş ülkelerde ise temas ve inhalasyon yolu ile bulaş daha çok görülmektedir $[1,4]$. Et ürünleri nadiren enfeksiyon kaynağı olmaktadır. Insandan insana bulaş çok nadirdir $[1,2,5]$. Cinsel temasla bulaştığı ileri sürülen vakalar bildirilmiş olup, epididimoorşitli hastaların sperm sıvısında bakteri üretilebilmektedir [6]. Hastalığın kan transfüzyonu ile bulaşabildiğini gösteren çalışmalar vardır. Anne sütü kaynaklı olgu bildirimleri de vardır [1, 7-9]. Ülkemizde ve hastalığın endemik olduğu ülkelerde başlıca bulaş kaynağı pastörize edilmemiş süt ürünlerinin tüketimiyledir [10]. Brusellozun önlenmesinde hayvanlar için etkili canlı attenüe aşılar kullanılmaktadır. Hayvanlardan bulaşın önlenmesinin en önemli yolu hayvanların aşılanmasıdır ancak insanlarda hastalığın önlenmesi için bir aşı bulunmamaktadır [11]. Bruselloz, Birleşmiş Milletler Gıda ve Tarım Teşkilatı (FAO), Dünya Sağlık Örgütü (WHO) ve
Dünya Hayvan Sağıı̆ı Örgütü (OIE) tarafından dünyadaki en yaygın zoonotik hastalık olduğu kabul edilmiştir [1, 2, 9]. WHO'nun verilerine göre; her yıl 500.000 yeni vaka saptanmaktadır. Hastalık Akdeniz ülkeleri, Orta Doğu, Batı Asya, Latin Amerika ve Afrika'nın bir bölümünde daha fazla görülmektedir [8, 12]. Türkiye'de bu bölgeler içindedir.

Bruselloz, herhangi bir organ sistemini tutulabilen sistemik bir hastalıktır [1]. Ayrıca Brucella'nın farklı türlerinin neden olduğu farklı klinik sendromlar da vardır. Hastalığın ilk döneminde en çok ateş (\%90-95), titremeterleme (\%40-90), halsizlik (\%80-95), yaygın kas ağrıları (\%40-70), eklem ağrıları (\%20 -40), iştahsızlık, baş ağrısı, sırt ağrısı, mental durgunluk hali gibi semptomlar görülür $[6,9]$. Ateş, üşüme ve titreme ile birlikte $40-41^{\circ} \mathrm{C}$ 'ye yükselip, çoğunlukla gece yarısından sonra terleme ile düşer. Hastalık ilerledikçe tabloya gastrointestinal semptomlar (karın ağrısı, bulantı, kusma, sarılık, ishal ve/veya kabızlık) da eklenebilir $[4,12]$.

Hastanemizde çalışan, sağlık görevlilerinin dışındaki personelin ülkemizde yaygın görülen ve yüksek morbiditeye sahip olan bu hastalık hakkındaki bilgi, tutum ve davranışlarını değerlendirmeyi amaçladık.

\section{Gereç ve yöntem}

\section{Evren, örneklem ve veri toplama araçları}

Araştırmanın verileri, Pamukkale Üniversitesi Hastanesinde, personelin dinlenme saatlerinde, bir öğretim üyesi ve üç araştırma görevlisi tarafından, 25 soruluk anket formu, yüz yüze görüşme tekniği ile toplanmıştır. Pamukkale Üniversitesi Girişimsel Olmayan Klinik Araştırmalar Etik Kurulu Başkanlığı'ndan etik kurul onayı alındı.

\section{Dahil etme kriterleri}

Çalışmaya dahil olmak için onam veren 18 yaşından büyük, çalışmanın yapıldığı tarihlerde hastanemizde görev yapan personeller çalışma kapsamına alındı. 


\section{Dışlama kriterleri}

Çalışmaya dahil olmak istemeyen personeller çalışmadan dışlandı.

\section{İstatistiksel değerlendirme}

Araştırma verileri Statistical Package for Social Sciences (SPSS) 18.0 programı ile analiz edildi. Verilerin değerlendirilmesinde tanımlayıcı istatistikler, ki-kare testi kullanıldı ve grup içi farklılık Mann Whitney $U$ testi ile analiz edildi. Bulgular $p<0,05$ anlamlılık düzeyi ile yorumlandı.

\section{Bulgular}

Katılımcıların 1/3'ünden fazlası $(\% 40,7)$ temizlik personeliydi. Bunu sırasıyla, hasta bakıcı $(\% 29,2)$, işçi $(\% 19,9)$, teknisyen $(\% 7,9)$ ve mühendis $(\% 2,3)$ izlemekteydi. Ankete katılan personelin sosyodemografik özellikleri Tablo 1'de özetlenmiştir. Çalışmaya katılan 216 kişiden 172'si Bruselloz ve/veya Brusellozun diğer isimlerinden en az birini duyduğunu belirtmiştir (Tablo 2). 172 kişinin 14'ü $(\% 8,14)$ duyduğu isimlerin hepsinin aynı hastalık olduğunu, 38'i $(\% 22,09)$ birkaçının aynı hastalık olduğunu bildiğini söylerken, 75’i $(\% 43,60)$ duyduğu isimlerin aynı hastalık olduğunu bilmediklerini söylemiş, 89 kişi $(\% 51,74)$ ise bu soruya cevap vermemiştir. Bruselloz ve/ veya Brusellozun diğer isimlerinden en az birini duyduğunu belirten 172 kişiden 53'ü bilgilerini çevrelerinden (arkadaş, akraba, komşu) öğrendiklerini söylemiştir ve bu grup $\% 30,81$ ile en yüksek oranı oluşturmaktadır. Diğer katılımcılar arasından sıklık sırasına göre 36 kişi $(\% 20,93)$ Brusellozu televizyon, radyo ve gazeteden, 26 kişi $(\% 15,12)$ ise veteriner hekimden öğrendiğini belirtmiştir.

Tablo 1. PAÜ Hastanesi personelinin sosyodemografik özellikleri

\begin{tabular}{|c|c|c|}
\hline Sosyodemografik Özellikler & Sayı & $\%$ \\
\hline \multicolumn{3}{|l|}{ Cinsiyet } \\
\hline Kadın & 113 & 52,3 \\
\hline Erkek & 103 & 47,7 \\
\hline \multicolumn{3}{|l|}{ Yaş } \\
\hline$\leq 29$ & 19 & 8,8 \\
\hline $30-39$ & 91 & 42,13 \\
\hline $40-49$ & 92 & 42,59 \\
\hline $50-59$ & 14 & 6,48 \\
\hline \multicolumn{3}{|c|}{ En küçük yaş: 20 En büyük yaş: 57} \\
\hline \multicolumn{3}{|c|}{ Mean $\pm \mathrm{SD}=39,35 \pm 6,552$} \\
\hline \multicolumn{3}{|l|}{ Median $=39,00$} \\
\hline \multicolumn{3}{|l|}{ Öğrenim Durumu } \\
\hline Okuryazar & 1 & 0,47 \\
\hline İlkokul & 69 & 31,94 \\
\hline Ortaokul & 40 & 18,52 \\
\hline Lise & 89 & 41,20 \\
\hline Önlisans & 13 & 6,02 \\
\hline Lisans & 4 & 1,85 \\
\hline \multicolumn{3}{|l|}{ Ekonomik Durum } \\
\hline Kötü & 50 & 23,15 \\
\hline Orta & 138 & 63,89 \\
\hline İyi & 28 & 12,96 \\
\hline Toplam & 216 & \\
\hline
\end{tabular}


Tablo 2. PAÜ Hastanesi personelinin Bruselloz ve/veya Brusellozun diğer isimleri hakkındaki bilgisi

\begin{tabular}{llcc}
\hline Bruselloz ve / veya Brusellozun Diğer İsimlerini Biliyor mu? & Sayı & $\%$ \\
\hline Hayır & 44 & $20,37^{* *}$ \\
Evet & Peynir hastalığı & 172 & $79,63^{* *}$ \\
$\quad$ Bruselloz & 102 & $59,30^{*}$ \\
$\quad$ Mal hastalığı & 74 & $43,02^{*}$ \\
$\quad$ Yavru atma hastalığı & 46 & $26,74^{*}$ \\
$\quad$ Malta humması & 16 & $9,30^{*}$ \\
$\quad$ Dalgalı humma & 10 & $5,81^{*}$ \\
\hline
\end{tabular}

*n=172 değerine göre yüzde değerleri, ** $n=216$ değerine göre yüzde değerleri

Bruselloz ve/veya Brusellozun diğer isimlerinden en az birini duyduğunu belirten 172 kişiye, Bruselloz hastalığında görülen şikâyetler sorulduğunda en sık "ateş" $(\% 40,12)$ cevabı verilirken, bunu sırasıyla "kas ağrısı" $(\% 27,33)$, "eklem ağrısı" (\%24,42), "terleme" (\%24,42), "halsizlik" (\%24,42), "bulantı-kusma" (\%18,60), "bel ağrısı" (\%15,70), "baş ağrısı" $(\% 15,12)$ ve "döküntü" $(\% 2,91)$ izlemektedir. Katılımcılardan 59 kişi $(\% 34,30)$ ise Bruselloz hastalığında görülen şikâyetler hakkında herhangi bir fikirleri olmadığını söylemiştir. Bruselloz ve/ veya Brusellozun diğer isimlerinden en az birini duyduğunu belirten 172 kişiye Brusellanın bulaş yolları sorulduğunda, en sık sokakta satılan kaynatılmamış sütle $(\% 49,42)$ bulaştığı cevabı verilirken, bunu sırasıyla pazarlardan alınan açık peynir $(\% 46,51)$, kırmızı et/sakatat ürünlerinin çiğ/az pişmiş tüketilmesi (\%20 ,35) ve koyun, keçi, inek gibi hayvanlarla/ bunların çıkartılarıyla direk temas $(\% 18,02)$ ile bulaş cevapları izlemiştir. Brusellanın bulaş yollarından biri olmamasına rağmen, 21 kişi $(\% 12,21)$ Brusellanın yoğurtla da bulaşacağını düşündüklerini ifade etmiştir. Bruselloz ve/ veya Brusellozun diğer isimlerinden en az birini duyduğunu belirten 172 kişinin yaklaşık beşte biri $(\% 20,35)$ Brusellozun sık rastlanan bir hastalık olmadığını söylemiştir.

Brusellozun tedavisi olup olmadığı sorulduğunda katılımcıların 70'i (\%32,40) hastalığın tedavisinin olduğunu söylemiştir.
Bruselloz ve/veya Brusellozun diğer isimlerinden en az birini duyduğunu belirten 172 kişiye Brusellozun insanlar ve hayvanlar için aşısı olup olmadığı sorulduğunda, katııımcıların yarısından fazlası $(\% 60,8)$ bilmediklerini söylemişlerdir. 8 kişi $(\% 4,7)$, Brusellozisin insanlar için aşısı olmadığını, 10 kişi ise $(\% 5,8)$ hayvanlar için aşısı olduğunu söylemiştir. Ankete katılan kişilerin büyük çoğunluğu $(\% 59,26)$ sütü marketten kutu ve/veya şişe süt şeklinde aldıklarını söylemiştir. Katıımcılara, tükettikleri peynirin kaynağı sorulduğunda, çoğunluğu peyniri marketten kapalı kutu şeklinde aldığını söylemiştir. Katılımcılara Brusellanın alınan açık sütün kaynatılmadan tüketilmesiyle bulaşıp bulaşmadığı sorulduğunda öğrenim durumu ilkokul ve altı olanların \%35,7'si, ortaokul olanların $\% 25$ 'i, lise ve üstü olanların $\% 47,2$ 'si bulaştığını belirtmiştir $(p=0,038)$. Brusellanın kutu süt ile bulaşmamasına rağmen kendisi ve/ veya etrafındakilerden herhangi biri geçirmiş olan katılımcıların \%5,1'i, kendisi ve/veya etrafındakilerden herhangi biri geçirmemiş olanların ise $\% 9,7$ 'si kutu süt ile bulaştığını ifade etmiştir $(p>0,05)$. Yoğurt Brusella bulaşına neden olmadığı halde hastalığı kendisi ve/ veya etrafındakilerden herhangi biri geçirmiş olan katılımcıların \%27,4'ü, kendisi ve/veya etrafındakilerden herhangi biri geçirmemiş olan katılımcıların ise \%52,4'ü yoğurdun Brusella bulaşına neden olduğunu ifade etmiştir $(p=0,01)$. Katılımcıların, Brusellanın bulaş yollarından birinin kırmızı et olup olmadığını bilme oranına 
bakıldığında öğrenim durumu yükseldikçe bulaşı bilme oranının arttığı görülmüştür $(p=0,036)$. Bu farkın nedeninin kişilerin sosyal çevresinden kaynaklanıyor olabileceği düşünülmüştür. Katılımcıların, kendisi ve/veya çevresinden birileri Bruselloz geçirmiş olanlarının \%4,6'sı açık sütün kaynatılmamasıyla yapılan peyniri tükettiklerini belirtirken, Bruselloz geçirmeyen grupta bu oran \%6,5'dir.

Ankete katılanlardan 68 kişi $(\% 31,48)$ son bir yıl içinde inek, koyun, keçi gibi hayvanlarla temas etmediklerini söylemiştir. Hayvanların sevilmesi ve oynanması ile Brusellozdan bulaş olmamakla birlikte katılımcıların önemli bir kısmı $(\% 82,7)$ sevme-oynama şeklinde temas ettiklerini ifade etmişlerdir. Kurban kesme $(\% 14,2)$ sebebiyle temas, sevme-oynamadan sonra ikinci sırada yer almaktadır. Katılımcılara, bu gibi hayvanlarla temas öncesi önlem alıp almadıkları sorulduğunda, 126 kişi $(\% 58,33)$ bir önlem aldıklarını ve bu önlemlerin en sık belirtilen hayvana yaklaşmama $(\% 44,43)$ ve el yıkama $(\% 41,27)$ olduğunu bildirmişlerdir.

Katılımcıların son bir yıl içinde inek, koyun, keçi gibi hayvanlarla temas durumunun, cinsiyetlerine göre dağılımına bakıldığında erkeklerin \%57,1'i, kadınların ise \%10,2'si bu gibi hayvanlarla temasta bulunduğu görülmüştür. Aradaki fark, istatistiksel olarak anlamlıdır $(p<0,05)$. Bu farkın oluşmasında, kadınların hayvanlardan korkması, kurban kesmek için hayvan alımını ve kurban kesimini sıklıkla erkeklerin yapmasının etkili olduğu düşünülebilir. Katılımcıların cinsiyetlerine göre inek, koyun, keçi gibi hayvanlarla temas öncesi önlem alma durumlarına bakıldığında, erkeklerin \%47,3'i, kadınların ise \%72,3'ü temas öncesinde herhangi bir önlem aldığını belirtmiştir $(p<0,05)$. Erkekler, kadınlara göre, hayvanlarla daha sık temas etmelerine rağmen, erkeklerin temas öncesi önlem alma sıklığı kadınlara göre daha düşüktür.

Son bir yıl içinde inek, koyun, keçi gibi hayvanlarla temas durumunun dağılımına bakıldığında kendisi ve/veya etrafındaki herhangi biri Bruselloz geçirmiş olanların $\% 58,06$ 'sı, geçirmemiş olanların ise $\% 17,13$ 'ü temas ettiklerini belirtmiştir.

\section{Tartışma}

Araştırmaya katılanların \%52,3'ü kadın, \%47,7'si erkektir. Araştırmaya katılan kadınların sayısının erkeklerden daha fazla olması, araştırmaya dahil olmak isteyen kişilerin çoğu kadın olması ile açıklanabilir.

Katılımcılara Bruselloz’la ilgili bilgi kaynakları sorulduğunda en çok "çevre" yanıtı verilmiştir. $\mathrm{Bu}$ durumun nedeni, hastanede çalışmalarına rağmen hastalıklarla ilgili soru sormaya çekinme, eğitim kurumlarının ve medyanın bu konuda yeterli bilgiyi ulaştırmıyor olması ve hastalık deneyimlerinin daha akılda kalıcı olması olabilir.

Türkiye Bruselloz açısından endemik bir ülke olmasına rağmen katılımcıların \%20,45'i bu hastalığın sık görülmediğini, \%60,61'i ise bu konuda bir fikirlerinin olmadığını belirtmiştir. Brusellozdan korunmak için insanlara uygulanan bir aşının bulunmamasına rağmen katılımcıların \%11,6'sından 'vardır' yanıtı alınmıştır.

"Rusya'da 2003-2005'te Bruselloz epidemiyolojisi ve tanı metotları" derlemesine göre Bruselloz hastalığı \%63,9 oranında erkeklerde görülmekte ve vakaların \%68,1'ine temas ile, \%23,9'sına gıda ile bulaşmıştır, kalan \%8'de bulaş yolu tespit edilememiştir. Değerlendirilen 1462 vakanın \%29,3'ü Brusella ile iş yerinde karşılaşmıştır, \%70,7'sinde bu bağlantı bulunamamıştır. 2003-2005 yılları arasında başvuran vakaların \%50'sinden fazlanın 40 yaşından genç olduğu görülmüştür. \%12,2'si çocuk ve ergen, \%37,4'ü 20-39 yaş arasında, \%42,3'ü 40-59 yaşların, \%8,1'i 60 yaş ve üstündedir [13]. Bizim çalışmamıza katılanların \%84,72'si 30-49 yaş arasındandır. Bizim verilerimizin Rusya ile farklılık göstermesinin nedeni anketi uyguladığımız katılımcıların hastanede çalışan, çalışma hayatında aktif olan yaş grubu mensupları olmasından kaynaklanabilir.

Avcı ve ark.'nın [14] Van'ın bazı köylerinde yaptıkları bir çalışmada katılımcıların $(n=66)$ $\% 98,5$ 'inin Bruselloz hastalığını duyduklarını, \%47'sinin Brusellozdan nasıl korunulacağını bilmediğini saptamışlardır. Çalışmaya katılanların \%95,5'nin çiğ sütten peynir yaptıkları saptanmıştır. Çalışmaya katılanların tamamının çiğ sütten yaptıkları peynirleri taze olarak ve/veya bir aydan kısa sürede tuzlu suda/salamurada bekleterek kullandıkları ve/veya sattıkları saptanmıştır. Çalışmaya katılanların yarısına yakını önceden Bruselloz tanısı aldığını belirtmiştir. Akkuş ve ark. [15] yaptıkları benzer bir çalışmada Kars ilinde 
hayvancılıkla uğraşan 97 kişinin Bruselloza ilişkin bilgi ve uygulamalarını sorgulamıştır. Katılımcıların değerlendirilmesinde; \%84'ünün çiğ sütten peynir yaptığı, \%19'unun peyniri hemen kullandığını, \%66'sının çiğ kaymaktan tereyağını yaptığı, \%66'sının Brusellozu duyduğu, \%35'inin hayvanında yavru atma, \%32'sinde ölü doğum olduğu belirlenmiştir.

Bizim çalışmamızda Brusellozun bulaş bilgisi hastalığın herhangi bir ismini duyan 172 kişi üzerinden değerlendirilmiştir. Bulaş yollarına en sık verdikleri cevaplar sırasıyla, "kaynatılmamış süt”, "taze peynir" ve "az pişmiş/ çiğ kırmızı et” olmuştur. Brusellanın bulaş yolları çoğunlukla doğru bilinirken, yoğurtla bulaş olmamasına rağmen 21 kişi 'yoğurtla bulaşır' yanıtını vermiştir. Bunun sebebinin yoğurdun kaynatılmış sütten yapıldığını bilmemeleri ve kendilerinin evde yoğurt yapmamaları olabilir.

Brusellanın bulaş yollarını bilme ile öğrenim durumu arasında anlamlı bir fark bulunmuştur. Öğrenim seviyesi arttıkça bulaş yolları daha az bilinmiştir. Bununla ilgili olarak daha spesifik çalışmalara gerek olabilir. Ancak bunun sebep olarak köy yaşantısından şehir yaşamına geçişin etkili olduğu düşünmekteyiz. Kutu süt ile bulaş olmazken 14 kişi kutu süt ile bulaştığını belirtmiştir. Bunun sebebi halk arasında kutu süt olarak bilinen işlenmiş sütlerin aslında çiğ sütün $135^{\circ} \mathrm{C}$ 'nin üzerinde ısıtılarak, Ultra Yüksek Isı veya Isıl İşlemler (pastörizasyon, sterilizasyon ve UHT gibi teknikler) görmüş olduğunu bilmemeleri olabilir.

Kendisi ve/veya çevresinden birileri Bruselloz geçirmiş olanlarda kaynatılmış süt ve kaynatılmış sütten yapılan peynirin tüketiminin daha fazla olması, kendisi Bruselloz geçirmiş olan kişilerin kaynatılmamış açık sütü veya kaynatılmamış açık sütten yapılmış peyniri tüketmemeye dikkat ettikleri görülmüştür. Ayrıca kendisinin ya da çevresinden birilerinin hastalık hikayesi olan kişilerin Bruselloz bulaşma yollarını bilme oranı, kendisi ya da çevresinde hastalık öyküsü olmayanlara göre daha anlamlı olarak daha fazladır. Bunun sebebinin hastalık geçirmenin bilinçlenmeye etkisi olduğunu düşündürmektedir.

Bizim çalışmamızda Avcı ve ark. [14] ile Akkuş ve ark.nın [15] çalışmalarına göre çiğ sütten peynir yapımı daha az oranda görülmüştür. Bunun sebebinin ise bölgesel yemek kültürü farklılıklarından kaynaklandığını düşünmekteyiz.

Kendisinin ya da çevresinden birilerinin hastalık hikayesi olan kişilerin Bruselloz bulaşma yollarını bilme oranı, kendisi ya da çevresinde hastalık öyküsü olmayanlara göre daha anlamlı olarak daha fazladır. Bu, hastalığı geçirmenin bilinçlenmede etkili olduğunu düşündürmektedir.

Tüketilen peynirin kaynağı ile hastalıktan haberdar olma arasında anlamlı ilişki tespit edilememiştir. Katılımcıların bu davranışlarının sebebinin hastalığı duymalarına rağmen hastalık hakkında yetersiz bilgiye sahip olmaları olabilir. Hayvanla temas sonrasında alınacak önlemler sorulduğunda, 56 kişinin "hayvana hiç yaklaşmam" cevabı en sık alınan cevap olurken, el yıkama ise 52 kişi tarafından en çok alınacak ikinci önlem olmuştur.

Sonuç olarak; Brusellozun Türkiye'de endemik bir hastalık olmasına rağmen hastane çalışanları tarafından da iyi bilinen bir hastalık olmadığı görülmüştür. Bilgi edinmenin çoğunlukla sosyal öğrenmeyle gerçekleştiğini gördüğümüz çalışmamızda, bu durumun yanlış, eksik bilgilenmelere de sebep olabileceği düşünmekteyiz. Özellikle hastalığın yayıımasının önlenmesi için daha fazla toplumsal bilinçlendirme ve farkındalık çalışmalarına gerek duyulmaktadır.

Çıkar ilişkisi: Yazarlar çıkar ilişkisi olmadığını beyan eder.

\section{Kaynaklar}

1. Zoonotik hastalıklar hizmet içi eğitim modülü. T.C. Sağlık Bakanlığı Temel Sağlık Hizmetleri Genel Müdürlüğü Zoonotik Hastalıklar Daire Başkanlığı, 2011. Erişim adresi: http://sbu.saglik.gov.tr/Ekutuphane/ kitaplar/Zoonotik\%20Hastaliklar\%20Katilimci\%20 Kitabi.pdf. Erişim tarihi 30.05.2020

2. Hatipoğlu ÇA, Kınıklı S, Tülek $N$, ve ark. Bir eğitim hastanesinin infeksiyon hastalıkları ve klinik mikrobiyoloji kliniğinde izlenen 202 bruselloz olgusunun epidemiyolojik verilerinin irdelenmesi. Klimik Derg 2005;18:94-98.

3. Şimşek F, Kantürk A. Bruselloz. Okmeydanı Tıp Dergisi 2016;32:46-49. https://doi.org/10.5222/otd.2016.046

4. Öcal N, Babür C, Yağcı BB, ve ark. Kırıkkale yöresinde süt sığırlarında brusellozis, listeriozis ve toksoplazmozis'in seroprevalansı ve birlikte görülme sıklığı. Kafkas Üniv Vet Fak Derg 2008;14:75-81. https://doi.org/10.9775/kvfd.2008.09-A 
5. Ulusal Mikrobiyoloji Standartları (UMS). Brusellozun mikrobiyolojik tanısı. T.C. Sağlık Bakanlığı, 2015. Erişim adresi: http://mikrobiyoloji.thsk.saglik.gov. tr/Dosya/tani-rehberi/bakteriyoloji/UMS-B-MT-19Bruselloz.pdf. Erişim tarihi 30.05.2020

6. Edward JY. Brucella species. In: Mandell GL, ed.Mandell GL, Douglas RG, Bennet JE. Principles and practice of infectious diseases 5th ed.Philelphia: Churchill Livingstone, 2000:2386-2393.

7. Çelebi S. Brusellozun epidemiyolojisi. ANKEM Derg 2003;17:340-343.

8. Pappas G, Papadimitriou P, Akritidis N, Christou L, Tsianos EV. The new global map of human brucellosis. Lancet Infect Dis 2006;6:91-99. https://doi.org/10.1016/ S1473-3099(06)70382-6

9. Doganay M, Aysen B, Esel D. Brucellosis due to blood transfusion. J Hosp Infect 2001;49:151-152. https://doi. org/10.1053/jhin.2001.1004

10. Soyaltın UE, Demir B, Öner Ö, Demirci T, Ekinci F, Akar H. Karaciğer enzim yüksekliği ve epigastrik ağrıyla kendini gösteren Bruselloz: üç olgu sunumu. Klimik Derg 2014;27:30-32. https://doi.org/10.5152/ kd.2014.08

11. Kandemir Ö. Bruselloz. Türkiye Klinikleri J İnf DisSpecial Topics 2015;8:1-9

12. Food and Agriculture Organization of the United Nations, World Organization for Animal Health, and World Health Organization. Brucellosis in human and animals. Geneva: World Health Organization; 2006. Erişim adresi: https://www.who.int/csr/resources/ publications/Brucellosis.pdf?ua=1. Erişim tarihi 05.06.2020

13. Denisov AA, Sclyarov OD, Salmakov KM, Shumilov KV. The Russian experience in brucellosis veterinary public health. Rev Sci Tech 2013;32:229-237. https:// doi.org/10.20506/rst.32.1.2199

14. Avcı DK, Şahin HA, Güvendi G, Çakmak Z, Van iline bağlı bir köyde hayvancılıkla uğraşan bireylerde Bruselloz'a ilişkin bilgi, tutum ve davranışların belirlenmesi. Van Tıp Derg 2017;24:78-84.

15. Akkuş $Y$, Karatay $G$, Gülmez A. Hayvancılıkla uğrașan bireylerin bruselloza ilișkin bilgi ve uygulamaları. Kafkas J Med Sci 2011;1:16-20. https://doi.org/10.5505/ kjms.2011.14633

Etik kurul onayı: Pamukkale Üniversitesi Girişimsel Olmayan Klinik Araştırmalar Etik Kurulu Başkanlığı'ndan 28/04/2020-08 sayılı kararı ile etik kurul onayı alındı.

\section{Yazarların makaleye olan katkıları}

M. Ö., A. Y. ve R. B. çalışmanın ana fikrini ve hipotezini kurgulamışlardır. M. Ö. ve A.Y. teoriyi geliştirmiş ve materyel metod bölümünü düzelemişlerdir. Sonuçlar kısmınındaki verilerin değerlendirmesini A. O. ve M. S. yapmışlardır. Makalenin tartışma bölümü M.Ö., A. Y. ve R. B. tarafından yazıımış, A. O. ve M. S. gözden geçirip gerekli düzeltmeleri yapmış ve onaylamıştır. Ayrıca tüm yazarlar çalışmanın tamamını tartışmış ve son halini onaylamıştır. 